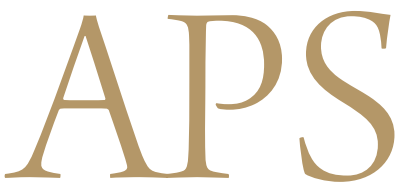

Archives of Plastic Surgery

\title{
A New Method for Creating a Definite Philtrum by the Flipping of an Orbicularis Oris Muscle Flap in a Patient with an Indistinct Philtrum
}

\author{
Hyun Nam Choi, Sin Rak Kim, Yea Sik Han \\ Department of Plastic and Reconstructive Surgery, Kosin University College of Medicine, Busan, Korea
}

The philtrum plays a key role in the appearance of the upper lip and nostril sill. Therefore, construction of the philtrum is crucial for attaining a natural appearance of the upper lip. We used a flipping myoplasty of the orbicularis oris muscle on a patient with a flat philtrum in order to effectively reconstruct the philtral dimple and column. A 35-year-old female presented to our department with the complaint of a flat upper lip. A superficial layer of the orbicularis oris muscle on the median aspect of the upper lip was vertically incised and elevated to a thickness of $2 \mathrm{~mm}$. Both sides of the elevated muscle flap were then folded to the lateral sides so that the border could be sutured onto the outer portion of the orbicularis oris muscle. The patient was observed for one year postoperatively. Her philtrum deepened by $1.25 \mathrm{~mm}$, with the central angle of her Cupid's bow improving from a preoperative measurement of $146^{\circ}$ to $128^{\circ}$ postoperatively. In a patient with an indistinct philtrum, a flipping orbicularis oris myoplasty was performed to attain a definite philtral column and a philtral dimple. Natural upper lip movement was maintained, and an aesthetically and functionally satisfactory reconstruction was achieved.

Keywords Lip / Surgical flaps / Reconstructive surgical procedure

\author{
Correspondence: Yea Sik Han \\ Department of Plastic Surgery, \\ Kosin University College of Medicine, \\ 262 Gamcheon-ro, Seo-gu, Busan \\ 602-702, Korea \\ Tel: +82-51-990-6131 \\ Fax: +82-51-990-3005 \\ E-mail: hanplastic1@naver.com
}

No potential conflict of interest relevant to this article was reported.

Received: 27 Oct 2012 • Revised: 24 Dec 2012 • Accepted: 25 Dec 2012

pISSN: 2234-6163 • elSSN: 2234-6171 • http://dx.doi.org/10.5999/aps.2013.40.1.62 • Arch Plast Surg 2013;40:62-65

\section{INTRODUCTION}

The philtrum, which derives from the Greek word philtron meaning "love potion," is the most characteristic feature of the upper lip, helping to create a natural appearance of the lip [1]. During lip motion, the philtral column and dimple are highlighted, helping a viewer form an impression of the speaker [2]. Morphological philtral disorders occur in patients with cleft lip, secondary cleft lip-nose deformity, and deformity after tumor resection or traumatic injury. A smooth philtrum is also a characteristic feature of fetal alcohol syndrome [3]. Herein, we report a simple and effective method for creating a philtrum by flipping myoplasty of the orbicularis oris muscle for a patient with a flat philtrum of unknown etiology.

\section{CASE}

A 35-year-old female patient presented to our department with the complaint of a flat upper lip. The patient had an ambiguous philtral column and philtral dimple, creating the appearance of an overall flat upper lip (Fig. 1). A faint scar was also observed $20 \mathrm{~mm}$ along the white roll of the central upper lip. 


\section{Fig. 1. Preoperative view}

(A) Preoperative front view. Central angle of the Cupid's bow was $146^{\circ}$. (B) Preoperative oblique view in which the flatness of the upper lip can be observed. cphR, crista philtri right; cphL, crista philtri left; Is, labiale superius.
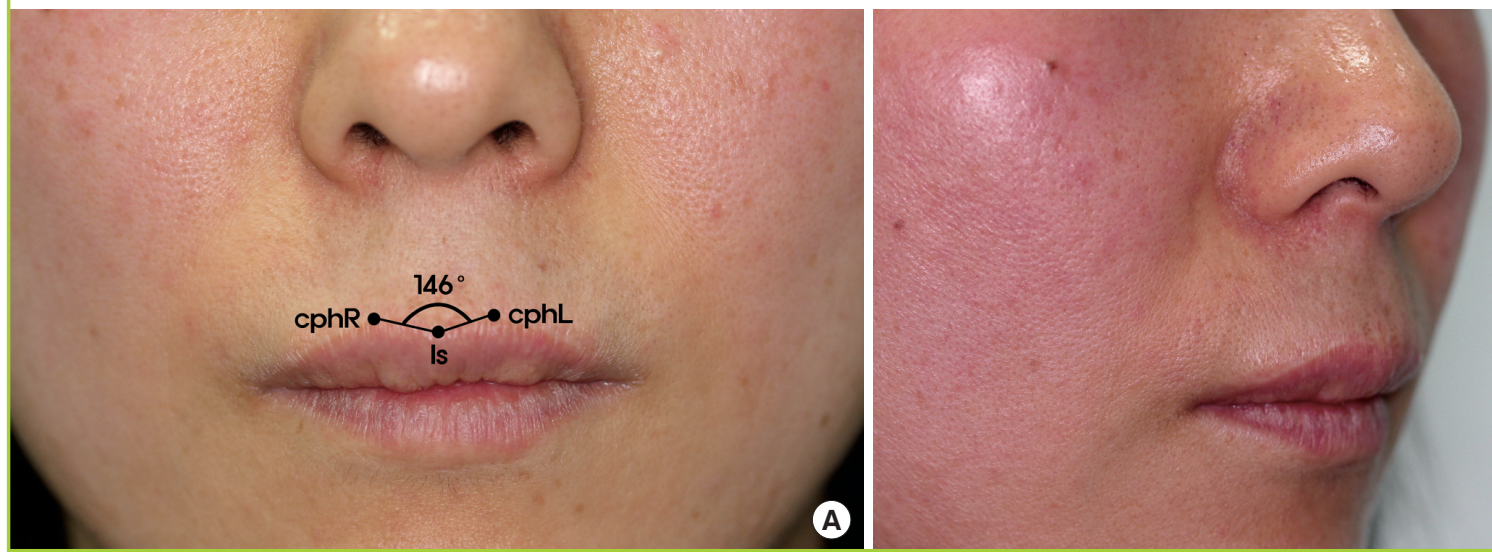

\section{Fig. 2. Schematic illustration of the surgical technique}

(A) Vertical incision of the orbicularis oris muscle flaps was performed. Dissection of the muscle flap was performed at the gentian violet markings. (B) Flipping of the bilateral muscle flaps was performed on the lateral sides. A quilting suture was placed on the skin flap of the upper central lip at the site where the muscular flap was elevated, creating a distinctive philtral dimple depression.

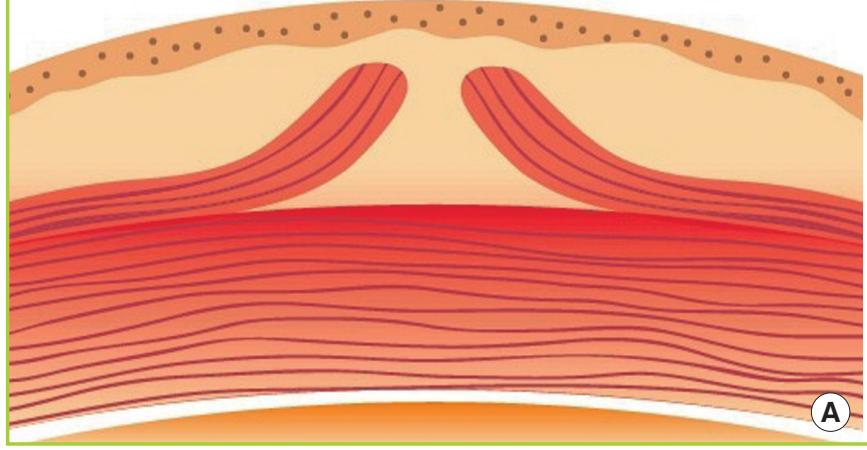

The patient was born normally at term, denied any history of trauma, and did not disclose any maternal alcohol use. In an attempt to correct the flat philtrum, triamcinolone had been injected in the midline of her upper lip three separate times 10 years earlier. Furthermore, the patient also underwent an operation 5 years earlier to achieve a definite philtrum. However, we were not able to determine the exact surgical procedure used based on observation.

Based on a previously published anthropometric analysis of the mouths of Koreans, a philtral reconstruction was designed so that the postoperative philtral width would be $12 \mathrm{~mm}$ at the peaks of the Cupid's bow and $10 \mathrm{~mm}$ at the columellar base [4]. Under local anesthesia, a 26 gauge needle dipped in gentian violet was used to puncture the area along the designated line, thus marking the orbicularis oris muscle at the area where a philtral column would be created. A linear incision was made. The subcutaneous dissection was done to the columellar base, so that this skin flap could be elevated. After dissection, a vertical inci-

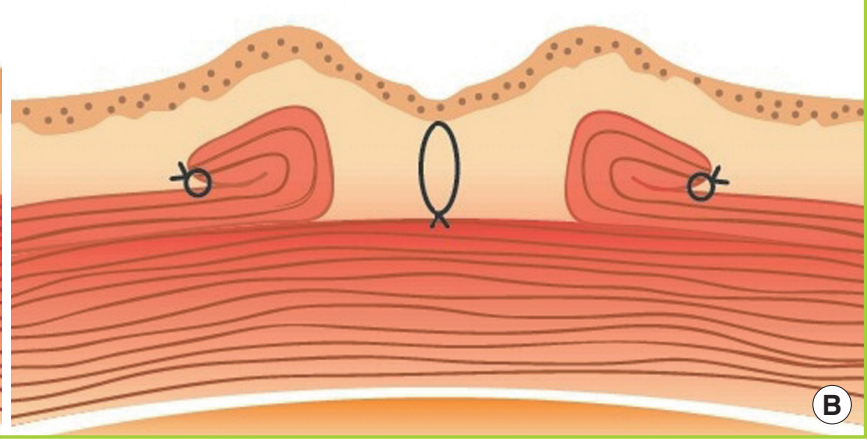

sion was made on a superficial layer of the orbicularis oris muscle of the central upper lip, and an orbicularis oris muscle flap about $2 \mathrm{~mm}$ thick was elevated to the area marked with gentian violet. Both sides of the elevated muscle flap were then folded to the lateral side. The incisional margin of the muscle flap was sutured using a horizontal mattress stitch onto the lateral portion of the orbicularis oris using an absorbable suture. In the area of the folded orbicularis oris muscle, the upper lip was allowed to thicken, forming a philtral column. A dermal quilting suture was also used in the area of the central upper lip where the muscular flap was elevated to make the philtral dimple more definite (Figs. 2, 3). The skin was then sutured using a non-absorbable suture. We tied an external central bolster to the new philtrum with a through-and-through nylon suture to provide additional external pressure and to accentuate the new philtrum formation. Five days later, these materials were removed from the surgical site. The patient was observed for one year postoperatively. Her philtrum deepened by $1.25 \mathrm{~mm}$, with the central angle of 


\section{Fig. 3. Surgical technique}

(A) The muscle flaps were completely exposed and split into two leaves. (B) Each muscle flap was flipped over and sutured to the lateral side.
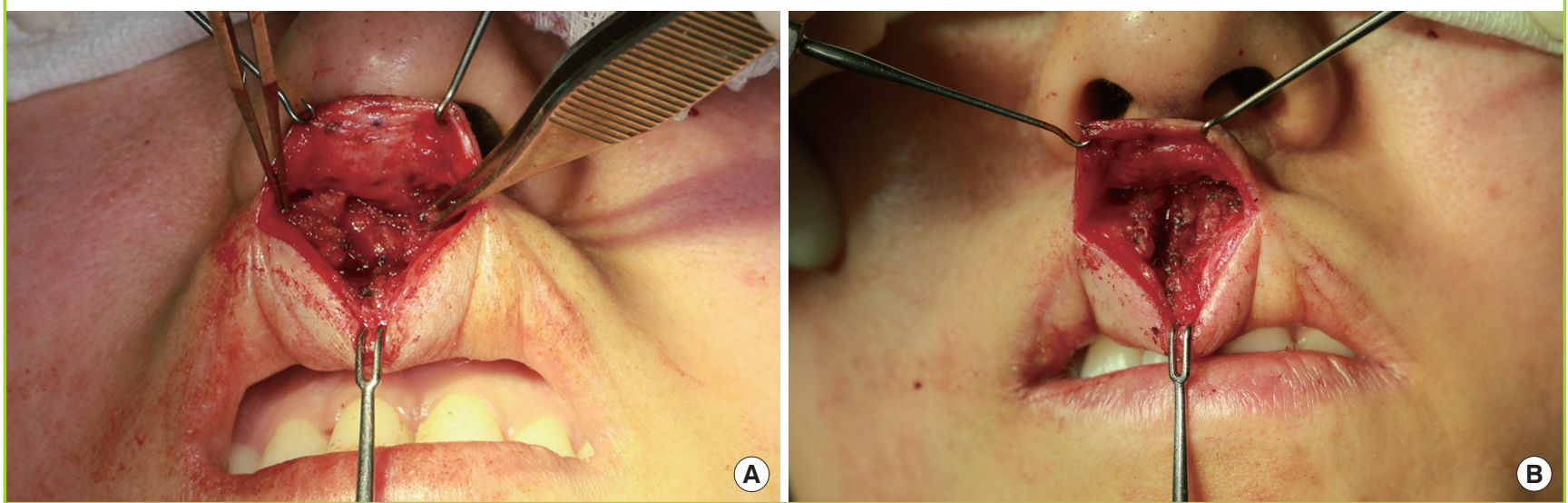

\section{Fig. 4. View 1 year postoperatively}

(A) Postoperative front view. Central angle of the Cupid's bow was $128^{\circ}$. (B) Postoperative oblique view. Elevation of the philtral column and depression of the philtral dimple were achieved by flipping myoplasty. cphR, crista philtri right; $c p h L$, crista philtri left; Is, labiale superius.

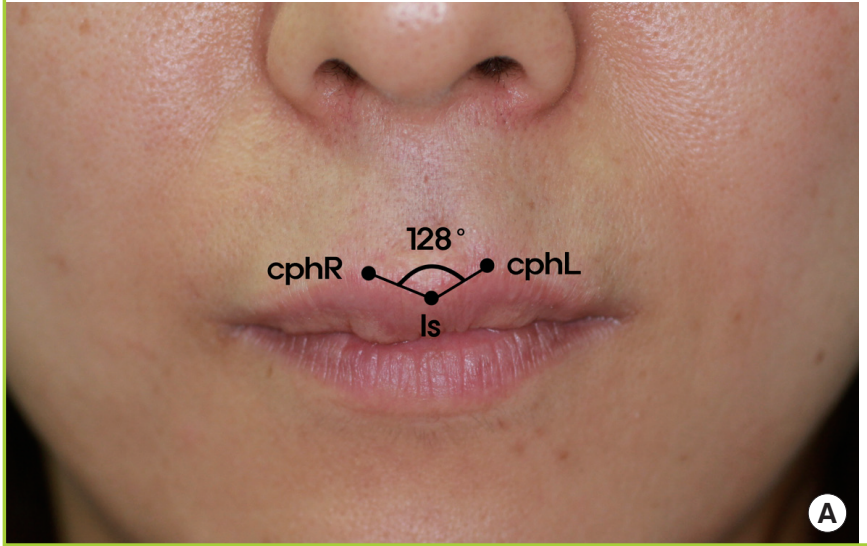

her Cupid's bow improving from a preoperative measurement of $146^{\circ}$ to $128^{\circ}$ postoperatively. Thus, philtral reconstruction, which enabled the patient to naturally move her upper lip, was achieved to her satisfaction (Fig. 4).

\section{DISCUSSION}

Physiologically, the upper lip protrudes slightly beyond the lower lip, with the philtral dimple, philtral column, and Cupid's bow defining part of the particular appearance of each individual. Although the functional significance of the philtrum is not obvious, it remains an important aspect of subjective beauty, contributing to a symmetric and natural-looking upper lip.

Morphological philtral defects are associated with many diseases, including holoprosencephaly and fetal alcohol syndrome [3]. However, indistinct philtrum also occurs idiopathically. In a study analyzing the philtral shapes of 55 Japanese adults without

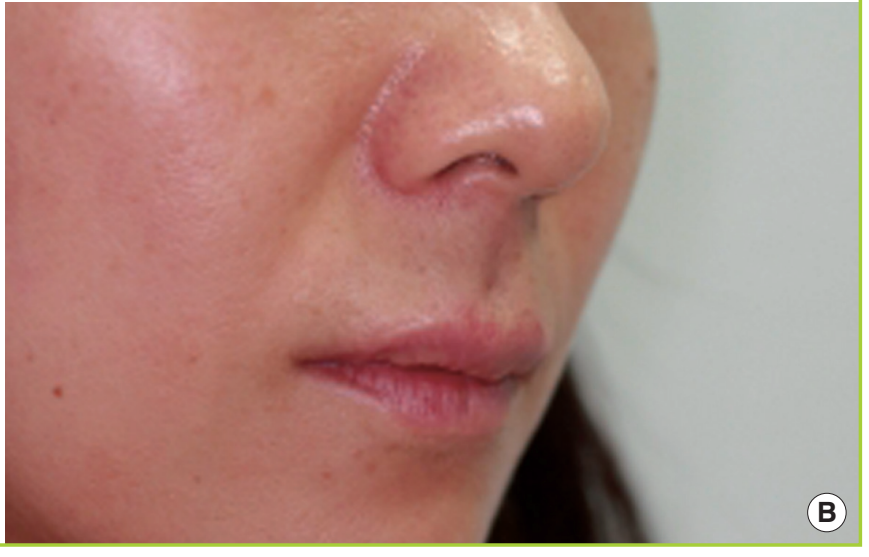

craniofacial disorders using the Uemura method, Kishi et al. [5] reported that 6 out of 30 females had an indistinct philtrum and that the philtral depth and the angle of the central Cupid's bow are objective parameters for determining the visual clarity of the philtrum. In that study, the average angle of the central Cupid's bow was $130.45^{\circ}$ among 25 males and $136.24^{\circ}$ among $30 \mathrm{fe}-$ males, while the philtral depths were $1.23 \mathrm{~mm}$ and $0.88 \mathrm{~mm}$, respectively. Another anthropometric analysis of the mouth in the Korean population by Kim et al. [4] reported that the average phitral width was $11.8 \mathrm{~mm}$ for males and $10.2 \mathrm{~mm}$ for females. Based on these studies, we planned phitral reconstruction to correspond to anthropometric analysis of the East Asian mouth. A variety of methods have been proposed for philtral reconstruction, including cutaneous upsweep, auricular cartilaginous composite grafts, and overlap and vertical interdigitation of the orbicularis oris [6-8]. Though many cases of philtral reconstruction have been reported in patients with cleft lip or other sec- 
ondary cleft lip-nose deformities, philtral reconstruction in an individual with an indistinct philtrum has never been described.

The reconstruction method described here using flipping myoplasty of the orbicularis oris muscle dissects only the superficial layer of the orbicularis oris muscle. It allows muscular continuity and does not create any obstacle in upper lip movement. It also allows the depression of the central tubercle and the elevation of both Cupid's bow points, and as a result, the central Cupid's angle is improved. Compared to existing surgical methods, our method has many advantages. By avoiding the use of implants, allografts, or cartilage from other areas, the method described here is able to create a natural upper lip and reduce associated costs without graft absorption or donor site morbidity. As the white roll of the upper lip is incised, no linear vertical scars are created. Moreover, there is no mucosal dissection, reducing the loss of the reconstructed philtral column into the oral cavity.

We used an approach through the scar on the white roll which was left from the previous operation. However, generally, the vermilion border, the distinct convex white roll, and the precise relation between these two structures are absolutely critical in lip repair. Therefore, in patients without a history of previous surgery, an approach between the wet and dry vermilion is recommended for the conservation of the integrity of the white roll and minimization of the scar.

A natural and definite philtrum was constructed in a patient with an indistinct philtrum through a flipping orbicularis oris myoplasty, and is an easy and effective method for reconstruction of the philtrum through anatomical rearrangement of the orbicularis oris muscle. Furthermore, as natural upper lip movement was maintained, an aesthetically and functionally satisfac- tory reconstruction was achieved.

\section{REFERENCES}

1. Kwon SM, Park J, Yang WY, et al. Reconstruction of philtral column with overlapping of orbicularis oris muscle flap in secondary cleft lip nose deformity. J Korean Soc Plast Reconstr Surg 2008;35:574-80.

2. Kim SW, Jeong YW, Cheon JE, et al. Oribicularis oris muscle defects in philtral deformities in the repaired cleft lip. J Korean Soc Plast Reconstr Surg 2010;37:427-32.

3. Kishi N, Tanaka S, Iida S, et al. The morphological features and developmental changes of the philtral dimple: a guide to surgical intervention in cases of cleft lip. J Craniomaxillofac Surg 2012;40:215-22.

4. Kim SH, Kim NY, Lee SH, et al. Anthropometric analysis of the mouth in Koreans. J Korean Soc Plast Reconstr Surg 2008;35:139-46.

5. Kishi N, Tanaka S, Iida S, et al. Comprehensive evaluation of three-dimensional philtral morphology. J Craniofac Surg 2011;22:1606-11.

6. O'Connor GB, Mc GM. Surgical formation of the philtrum and the cutaneous upsweep; preliminary report. Am J Surg 1958;95:227-30.

7. Millard DR. Cleft craft. 1st ed. Boston: Little Brown \& Co.; 1977.

8. Cho BC, Kim SW. Philtrum formation in secondary unilateral cleft lip and microform cleft lip using vertical interdigitation of the orbicularis oris muscle. J Korean Soc Plast Reconstr Surg 2004;31:279-86. 